\title{
Global Environment Facility
}

GEF

September 2001

Washington D.C.

\section{A GUIDE FOR SELF-ASSESSMENT OF COUNTRY CAPACITY NEEDS FOR GLOBAL ENVIRONMENTAL MANAGEMENT}

Prepared by the GEF Secretariat with the assistance of UNITAR

in collaboration with UNDP, UNEP, the World Bank, FAO, UNIDO, the Secretariats of $\mathrm{CBD}, \mathrm{CCD}$ and UNFCCC 
1. In May 2001, the GEF Council approved the provision of funding for countries to undertake self assessments of capacity building needs. For this purpose, it invited "the GEF Secretariat, in collaboration with the Implementing Agencies and the Executing Agencies, to prepare and widely disseminate guidelines to assist countries to prepare project proposals for such assistance."

2. To assist countries in accessing GEF resources for the purpose of undertaking a self assessment of capacity building needs, the GEF Secretariat and collaborating agencies have prepared Operational Guidelines for the expedited funding of national self assessments of capacity building needs. These guidelines should be followed by countries when preparing proposals for GEF assistance. The guidelines have been widely distributed to countries and are available on the GEF website: http://www.gefweb.org/

3. The present document supplements the guidelines by describing methodologies that may be utilized in carrying out the self assessment of capacity building needs, and is intended to assist countries that may want additional direction in preparing the self assessments. Countries should use this document, or parts of it, as they deem necessary and appropriate.

4. This document was prepared in consultation with the GEF's Implementing Agencies, FAO, UNIDO as well as the Secretariats of the Convention on Biological Diversity, the Convention to Combat Desertification, and the UN Framework Convention on Climate Change. Consultations were also carried out with representative governments and NGOs. Nevertheless, it is fully recognized that this guide is a "work in progress" and that lessons emerging from national experiences in undertaking the self assessments should be incorporated into this guide. This document will therefore be subject to further revision taking into account the comments and suggestions received from interested stakeholders.

5. Please address your comments and suggestions to any of the following, or questions and requests for clarification to any of the following :

Senior Programme Coordinator, Environmental Programmes United Nations Institute for Training and Research (UNITAR)

Palais des Nations, 1211 Geneva 10, Switzerland

email: NCSA@UNITAR.ORG

Yuki Yoshimura

Program Officer, GEF Secretariat

1818 H Street NW,

Washington DC 20433, USA

email: yyoshimura@worldbank.org

John Hough

Principal Technical Advisor, UNDP - GEF

304 East $45^{\text {th }}$ Street,

New York NY 10017, USA

email: john.hough@undp.org 


\section{Possible Contribution and Use of This Guide}

National Capacity Self-Assessments for Global Environmental Management (NCSA) are intended to be entirely country driven processes, undertaken in accordance with country priorities and situations. No single methodology can be devised that can cover the entire spectrum of situations across countries. This guide has been developed on the basis of national and international experiences in assessing capacity building needs in different sectors, for use by countries at their own discretion. They are not prescriptive in any sense, either for preparing projects for GEF assistance, or for implementing those projects. The assessment methodologies and exercises presented in the document are purely illustrative and should be adopted, as appropriate, to meet national needs and circumstances. Most importantly, countries are encouraged to use any approach that they feel will enable them to accomplish the goals and objectives for undertaking their NCSA.

Some countries may find that the suggested process and activities are ambitious and potentially resource intensive. This concern may be particularly valid for countries that have not yet undertaken major activities to protect the global environment. In practice, however, many countries have already prepared thematic profiles and assessments that can provide a valuable starting point for and input to the NCSA. In those countries, the focus of the NCSA might therefore be on taking stock of existing reports and to develop a coherent and integrated national framework for global environmental management. Countries that are at an early stage of strengthening their global environmental management scheme, however, might want to place some emphasis on developing sound baseline information and setting priorities through the preparation of thematic profiles and assessments. Each country has, of course, the right to consider and decide on these types of issues in accordance with its own preferences and priorities. It is hoped that this guide can play a constructive role in this process. 


\section{Table of Contents}

1 GOAL AND OBJECTIVES OF THE SELF-ASSESSMENT 1

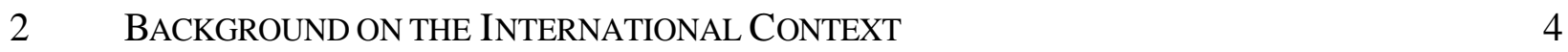

3 SugGeSted PRINCIPLES FOR THE NATIONAL CAPACITY SELF-ASSESSMENT PROCESS 8

4 DESIGNING AND EXECUTING THE NATIONAL CAPACITY SELF-AsSESSMENT Process 11

5 CONDUCTING A CAPACITY SELF-ASSESSMENT WITHIN THE THEMATIC AREAS OF BIODIVERSITY, CliMATE CHANGE AND DESERTIFICATION/LAND DEGRADATION

6 CONDUCTING A CAPACITY SELF-ASSESSMENT ACROSS THE THEMATIC AREAS OF BIODIVERSITY, ClimATE CHANGE AND DESERTIFICATION/LAND DEGRADATION

7 PREPARING THE NATIONAL CAPACITY SELF-ASSESSMENT DOCUMENT AND TAKING NEXT STEPS

ANNEX A $\quad$ BACKGROUND ON THE INTERNATIONAL CONTEXT

ANNEX B INDICATIVE REFERENCE LISTS TO DEFINE SUBSTANTIVE CONTEXT FOR CAPACITY DEVELOPMENT UNDER EACH THEMATIC AREA

ANNEX C OVERLAPPING REQUIREMENTS OF THE PARTIES TO THE RIO CONVENTIONS EXEMPLIFIED BY SELECTED ARTICLES 


$$
\text { pe }
$$




\section{ACRONYMS AND ABBREVIATIONS}

$\begin{array}{ll}\text { CBD } & \text { Convention on Biodiversity } \\ \text { CCD } & \text { Convention to Combat Desertification } \\ \text { CDI } & \text { Capacity Development Initiative } \\ \text { CDW } & \text { Country Dialogue Workshops } \\ \text { CILSS } & \text { Permanent Interstate Committee for Drought Control in the Sahel } \\ \text { CITIES } & \text { Convention on the International Trade in Endangered Species } \\ \text { COP } & \text { Conference of the Parties } \\ \text { CST } & \text { Committee on Science and Technology } \\ \text { EA } & \text { Environmental Agreement } \\ \text { GEF } & \text { Global Environmental Facility } \\ \text { IGAD } & \text { The Inter Governmental Authority for Development } \\ \text { NAP } & \text { National Action Programme } \\ \text { NBSAP } & \text { National Biodiversity Strategy and Action Plan } \\ \text { NCB } & \text { National Co-ordinating Body } \\ \text { NCSA } & \text { National Capacity Self- Assessment } \\ \text { NCSD } & \text { National Council for Sustainable Development } \\ \text { NEAP } & \text { National Environmental Action Plan } \\ \text { NGO } & \text { Nongovernmental Organisation } \\ \text { OSS } & \text { Sahara and Sahel Observatory } \\ \text { POPs } & \text { Persistent Organic Pollutant } \\ \text { RAP } & \text { Regional Action Programme } \\ \text { SIDS } & \text { Small Island Developing State } \\ \text { SRAP } & \text { Sub-regional Action Programme } \\ \text { UNCED } & \text { United Nations Conference on Environment and Development } \\ \text { UNDP } & \text { United Nations Development Programme } \\ \text { UNEP } & \text { United Nations Environment Programme } \\ \text { UNFCCC } & \text { United Nations Framework Convention on Climate Change } \\ \text { UNITAR } & \text { United Nations Institute for Training and Research } \\ \text { UNSO } & \text { Office to Combat Desertification and Drought } \\ & \end{array}$




$$
\text { pe }
$$




\section{Introduction}

GEF support for the preparation of National Capacity Self-Assessments (NCSA) is pursuant to the GEF Council Decision which "requests the GEF Secretariat, in collaboration with the Implementing Agencies and Executing Agencies, to initiate processes so that the self-assessment of capacity building needs can begin immediately in countries that request such assistance". "The overall aim of GEF support for the NCSA is to provide countries with the opportunity to take the lead in articulating their own capacity needs and priorities with respect to the global environment taking into account the three global conventions on biodiversity, climate change and desertification/land degradation. ${ }^{2}$

The primary goal of the NCSA is to identify, through a country-driven consultative process, priorities and needs for capacity building to protect the global environment. Specific objectives to be accomplished through the NCSA include, inter alia:

- to identify, confirm or review priority issues for action within the thematic areas of biodiversity, climate change and desertification/land degradation, respectively;

- to explore related capacity needs within and across the three thematic areas;

- to catalyse targeted and co-ordinated action and requests for future external funding and assistance; and

- to link country action to the broader national environmental management and sustainable development framework.

\section{Important Steps and Deliverables of the NCSA Process}

Over a course of approximately 12-18 months $^{3}$, interested countries, with financial resources from GEF, will have the opportunity to prepare a NCSA. A key deliverable of the NCSA process is a document which outlines - for each thematic area of biodiversity, climate change and desertification/land degradation as well as across the thematic areas - priority issues, capacity constraints and opportunities for capacity building.

\footnotetext{
${ }^{1}$ GEF, Joint Summary of the Chairs, GEF Council Meeting, May 9-11, 2001 "Decision on Agenda Item 7, Elements of strategic collaboration and a framework for GEF action for capacity building for the global environment".

2 The focus of the NCSA with regard to subject area is at each country's discretion. For example, a country may wish to focus exclusively on only one of the three thematic areas, place greater emphasis on a particular thematic area(s) or cover more than three thematic areas.

${ }^{3}$ The timeframe for undertaking the NCSA is flexible and will vary based on each country's unique situation. For example, a country may take 9-15 months to prepare the NCSA and an additional 12-18 months to monitor and update the results of the NCSA while related capacity building activities are developed and implemented.
} 
The approach suggested in this guide involves a number of phases (see Box 1). The first phase (see Part 5) would - building upon existing work already undertaken in the country - result in an assessment of capacity constraints within the three thematic areas of biodiversity, climate change and desertification/land degradation. Specific activities towards completing these assessments include the preparation of a "thematic profile" or "situation analysis" (if not yet existing); selection of a set number of priority issues; and identification of related capacity constraints. These three thematic assessments could form the basis for the identification of opportunities for thematic (see Part 5) and cross-cutting capacity building projects (see Part 6). Based on the output of both phases, countries may need to consider to develop a strategy for capacity building and sustaining the capacity developed, both within and across the thematic areas. A suggested

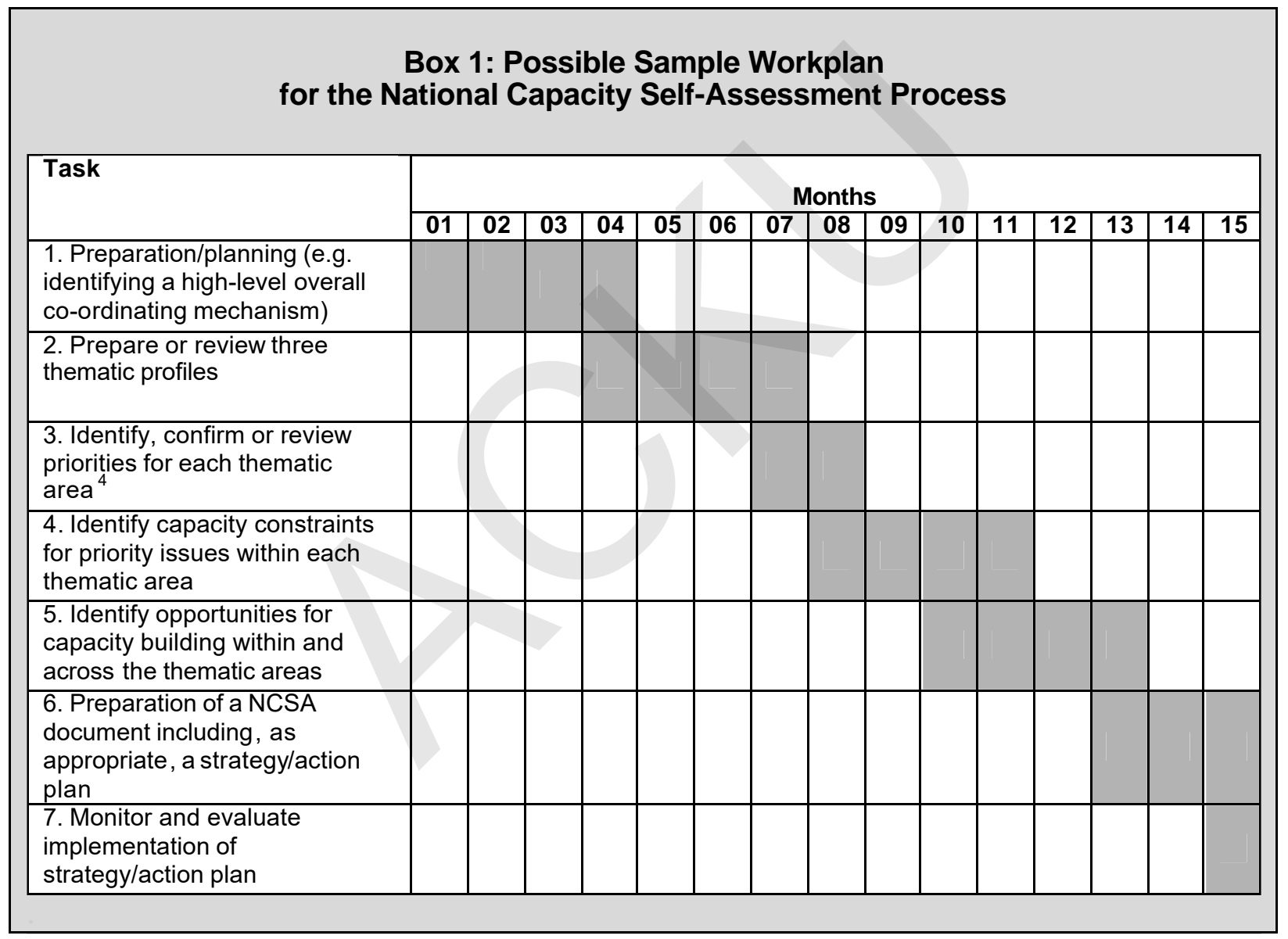

\footnotetext{
${ }^{4}$ Countries may find that for each thematic area, the two activities of preparing a thematic profile and priority setting, confirmation or review for that thematic area could be performed simultaneously. For example, if considerable information has already been collected, or if certain issues are known to be of particular importance despite the availability of existing thematic reports, the setting, confirmation or review of priorities can be initiated. Moreover, some areas that are common to more than one of the thematic areas may be immediately obvious or become apparent while preparing thematic profiles.
} 
Table of Contents for the NCSA document is presented in Part 7. A possible sample workplan for the NCSA is provided in Box 1 above. It should be kept in mind, however, that this is only a suggested approach for undertaking a NCSA and that countries may want to consider different approaches or modifying the suggested approach, as appropriate. ${ }^{5}$

\section{The Process of Preparing the NCSA Process}

An important part of preparing the NCSA is the process itself. A well-designed and comprehensive process can help to ensure that national action to build capacity to protect the global environment, as well as related requests for financial support are well-co-ordinated with and integrated into a nation's broader environmental management or sustainable development efforts. It is particularly important to identify and make use of existing co-ordinating structures at the national level, such as National Councils for Sustainable Development (NCSD) ${ }^{6}$, or more specialised co-ordinating mechanisms which are already in place in the thematic areas of biodiversity, climate change and desertification/land degradation. The NCSA process should bring together the various national agencies, institutions and organisations whose activities have important direct or indirect impacts on the environment, and will encourage them to assess gaps, identify synergies and devise a œ-ordinated approach for strengthening overall capacity. By putting in place or making use of existing mechanisms for consultation and co-operation, and by carrying out the necessary scoping, analysis and planning in an integrated fashion, countries could make significant progress in enhancing their capacity for global environmental management.

Undertaking a NCSA should be seen as a first step in a dynamic and long-term capacity building process. The NCSA should contribute to strengthening existing national programmes and should lead to targeted action plan development and implementation both within and across the thematic areas of biodiversity, climate change and desertification/land degradation. It should also help to identify linkages between global and national environmental management issues and capacity building efforts.

\footnotetext{
${ }^{5}$ For example, Small Island Developing States (SIDSs) in particular may wish to take a more streamlined, less complex, approach and work together at the regional level.

6 The 1992 Earth Summit (UNCED) recommended the active participation of citizens along with governments in implementation of the Rio agreements. Since then, more than 70 countries have established some form of a multi stakeholder participatory body, referred to here as NCSDs, to promote and implement sustainable development at the national level.
} 
The following presents a summary of international developments that are relevant to the NCSA process. Additional details concerning this international context for the NCSA can be found in Annex A.

\section{Strategic Planning, Reporting and Capacity Building Under the Three Rio Conventions}

Under the three Rio Conventions, namely the Convention on Biodiversity (CBD), the United Nations Framework Convention on Climate Change (UNFCCC) and the United Nations Convention to Combat Desertification (CCD), considerable discussion and activities have taken place to facilitate strategic planning and reporting and strengthen capacities in participating countries to comply with the respective obligations under each convention. These programmes, such as the GEF-funded UNDP National Communications Support Programme for the UNFCCC, have brought together a wide range of institutions in partner countries and often have catalysed and resulted in sustainable thematic co-ordinating mechanisms. These mechanisms, if still in place, may now be in a good position to make valuable contributions to both the thematic and integrated assessment components of the NCSA process. ${ }^{7}$

\section{Other Related Capacity Building Initiatives}

It is important to recognise that GEF supports a number of capacity building activities under other global conventions and instruments. Recent initiatives include support for countries to prepare National Implementation Plans for the Stockholm Convention on Persistent Organic Pollutants and capacity building activities related to the Cartagena Biosafety Protocol under the CBD. Other global instruments which have significant capacity building programmes include, for example, the Ramsar Convention on Wetlands of International Importance, the Convention on International Trade in Endangered Species (CITES), the Forest Principles ${ }^{8}$ and the Montreal Protocol on Substances that Deplete the Ozone Layer. In particular, the component of the NCSA process that addresses cross-cutting synergies is an appropriate point where relevant national activities conducted under these initiatives could be taken into consideration. In any case, establishing clear complementarity between environmental agreements (EAs) and the NCSA is likely to help ens ure a cost effective approach.

\footnotetext{
${ }^{7}$ Considering relevant activities in addition to particular administrative or organisational mechanisms and building on these will also help in this regard. Such activities include: GEF-supported Biodiversity Add-ons which enable countries to perform biodiversity-specific capacity needs assessments as a follow-up to the development of their National Biodiversity Strategy and Action Plans (NBSAPs), Biosafety capacity building activities, enabling activities of the Stockholm Convention on Persistent Organic Pollutant (POPs) and International Waters efforts, such as related assessments.

8 Non-legally Binding Authoritative Statement of Principles for a Global Consensus on the Management, Conservation and Sustainable Development of all Types of Forests.
} 


\section{Box 2: What is Meant by the Term "Capacity Building"? ${ }^{9}$}

The term "capacity building" is used in many contexts, often with little reflection regarding its meaning. Over the last few years experts from many countries have been moving towards a common definition of the term and there is now general agreement that "capacity building" can be taken as "the actions needed to enhance the ability of individuals, institutions and systems to make and implement decisions and perform functions in an effective, efficient and sustainable manner".

At the individual level, capacity building refers to the process of changing attitudes and behaviors, most frequently through imparting knowledge and developing skills through training. However it also involves learning by doing, participation, ownership, and processes associated with increasing performance through changes in management, motivation, morale, and levels of accountability and responsibility.

Capacity building at the institutional level focuses on overall organisational performance and functioning capabilities, as well as the ability of an organisation to adapt to change. It aims to develop the institution as a total system, including its constituent individuals and groups, as well as its relationship to the outside. In addition to improvements in physical assets, such as infrastructure, institutional capacity building involves clarification of missions, structures, responsibilities, accountabilities and reporting lines, changes in procedures and communications, and changes in the deployment of human resources.

At the systemic level capacity building is concerned with the creation of "enabling environments", i.e. the overall policy, economic, regulatory, and accountability frameworks within which institutions and individuals operate. Relationships and processes between institutions, both formal and informal, as well as their mandates, are important.

Capacity building can occur at local, national, or global levels and amongst any individual or group of stakeholders - individuals, entities or institutions, as well as at an overall systems level. Interactions between the different levels are also important to overall capacity. Capacity is relevant in both the short term (for example, the ability to address an immediate problem) and the long term (the ability to create an environment in which particular changes will take place). Capacity may imply "action", or "inaction", depending on the result desired. Capacity building does not always involve the creation of new capacity, but often the redeployment or release of latent capacities.

\footnotetext{
${ }^{9}$ Adapted from CDI, October 2000, Country Capacity Development Needs and Priorities: A Synthesis.
} 


\section{Development of Integrated Approaches to Capacity Building to Protect the Global Environment}

Implementation efforts by countries have revealed that many common obligations exist under the three Rio Conventions. These include, for example, requirements for research, reporting, training, public education, awareness and national exchange of information. While it is recognised that each convention stands on its own, with its own defined objectives and commitments, there is also an inherent relationship and mutual dependency between all of them. Consequently, there may be considerable importance and value in taking a holistic (i.e. crosscutting) approach to national strategy development and capacity building. Understanding the synergies among these conventions, and finding ways to co-ordinate and harmonise overlapping activities among them, are becoming increasingly recognised as ways to help to ensure effective national measures at the country level to protect the global environment.

Lessons learned from past projects seem to suggest a need in countries for capacity building measures to strengthen co-ordination of environmental policy formulation and implementation among sectoral authorities at the national (and local) levels for global environmental management. This includes, for example, development of capacity for:

- strengthening national procedures to negotiate and implement the global environmental conventions;

- integrating national data collection and reporting for the various conventions;

- enhancing research and monitoring activities that can meet the needs of more than one convention and increase the understanding of linkages; and

- strengthening connections between countries' convention-related reporting and thematic area programme priority-setting.

Perhaps the NCSA process can provide an opportunity to discuss these and related issues of integrated global environmental management at the national level and facilitate development of concrete initiatives that lead to synergistic approaches in addressing global environmental issues at the national level.

\section{Preparation of a Guide for NCSAs}

As a follow-up to the GEF Council meeting in May 2001, the GEF Secretariat has prepared this document to assist countries in thinking through various aspects of NCSA design and implementation. The document was prepared with the assistance of the United Nations Institute for Training and Research (UNITAR) which has developed, over the past years, experience in assisting countries to strengthen national multistakeholder platforms and capacity in various 
environmental domains, including support for self-needs assessments. ${ }^{10}$ Throughout the document preparation process, expertise available through GEF Implementing and Executing Agencies, in particular UNDP, as well as from the Convention Secretariats, were utilised. In addition, important input was provided by developing country experts in a peer review workshop organised by GEF in co-operation with UNITAR in September 2001.

\footnotetext{
${ }^{10}$ For example, UNITAR's National Profile Support Programmes, which comprise country-based guidance, training and technical support to assist countries in assessing their existing legal, institutional, administrative and technical infrastructures for certain environmental management issues (e.g. chemicals management), is considered to be of particular relevance to the NCSA process.
} 


\section{Suggested Principles for the National Capacity Self-Assessment PROCESS}

Taking into account experienced gained in countries regarding effective project and programme development and implementation, a series of key principles and processes are suggested for consideration in a national effort to undertake a self-assessment of country capacity needs. Integrating these principles into the NCSA process (and beyond) can help to ensure that such efforts have wide-spread support, are well-co-ordinated and undertaken with optimum efficiency, and increase the potential for sustainability. High-level involvement, for example, of the prime minister or national cabinet, could add value to the process (e.g. helping to secure necessary inkind resources, helping to emphasise linkages between capacity building to protect the global environment and national sustainable development efforts).

\section{- Ensuring National Ownership, Leadership and Policy Commitment}

The NCSA process and related capacity building activities should be nationally owned, led and driven. This involves national (and/or regional) experts playing a major role in the NCSA process. In addition, a high degree of national political commitment and leadership - which should be sustained beyond the NCSA process - is considered essential. Related implications of this principle are that country representatives decide on priorities and courses of action and identify links to other national environmental management priorities. It also implies selfmonitoring, self-evaluation and learning-by-doing.

\section{- Utilising Existing Co-ordinating Mechanisms and Structures Where Appropriate}

Efforts should be made to take advantage of existing consultative mechanisms and structures where appropriate, such as NCSDs, National Environmental Action Plans (NEAPs) and Agenda 21 Committees (also see Part 4). Doing so can help to avoid unnecessary overlap and duplication of effort, and will help to ensure that organisations and institutions that have been involved in related activities in the past will continue to be involved in determining co-ordinated priorities and follow-up action relating to the protection of the global environment in an integrated way.

\section{- Making Use of Provisions and Obligations of the Conventions}

Considerable discussion and negotiation have taken place regarding the various provisions and obligations of the Rio Conventions. Such efforts and information can provide important guidance and should be built upon. For example, particular attention should be paid to the frameworks for capacity building outlined by the UNFCCC COP. ${ }^{11}$

\footnotetext{
${ }^{11}$ UNFCCC, (FCCC/CP/2001/L.2), Review of the Implementation of Commitments and of Other Provisions of the Convention. Capacity-building. Draft decision proposed by the Co-Chairmen of the negotiating group, Draft decision -/CP.6, Capacity-building in developing countries (non-Annex I Parties) and UNFCCC, (FCCC/CP/2001/L.3), Review of the Implementation of Commitments and of Other Provisions of the Convention.
} 


\section{- Promoting Comprehensive Participation}

The NCSA process should ensure involvement of all affected and interested parties (including the wide range of relevant governmental ministries and agencies). In particular, the private sector has an increasing responsibility to foster sustainable development. An important aspect is the inclusion of stakeholders at the early and formative stages, especially when decisions are to be made on how the NCSA will be implemented. Involving stakeholders as early as possible may result in the identification of issues which might have otherwise been overlooked or not considered important, but which could prove to be of significant importance for certain stakeholders or for the matter in question.

\section{- Adopting a Holistic Approach to Capacity Building}

Effective capacity building requires a holistic approach. This involves recognising and addressing the various dimensions or levels of capacity, which include the individual, the institutional and the systemic (e.g. the overall policy framework in which individuals and organisations operate and interact with the external environment, and the formal and informal relationships between institutions). An inadequate emphasis to address problems at the systemic level may, for example, diminish the impact of efforts at the institutional and individual levels. A proper balance, therefore, needs to be established between all three, closely interlinked, levels of capacity building. A holistic approach also means ensuring co-ordination and complimentary efforts across sectors.

\section{- Adopting a Long-term Approach to Capacity Building within the Broader Sustainable Development Context}

The NCSA should be seen as a starting point - or a contribution - to a long-term process which strengthens thematic programmes and cross-cutting programmes under the Rio Conventions. In cases where such programmes are not in place, advantage could be taken of the NCSA process to initiate such programmes. If programmatic frameworks are in place, future projects based on the NCSA - to be funded by GEF and others - can be integrated into a more comprehensive national strategy which has a long-term vision and ensures long-term commitment.

The NCSA process should also be anchored in and contribute to broader environmental management and sustainable development plans. The NCSA should identify concrete opportunities for improvements, action plan development and projects which will strengthen the overall environmental management infrastructure at the national level. In some cases, such considerations may lead to environmental management projects which have both a national as well as global dimension, with joint funding provided both by GEF and other donors committed to strengthening the overall environmental management infrastructure in developing countries and countries with economies in transition. In addition, the NCSA could compliment other

Capacity-building. Draft decision proposed by the Co-Chairmen of the negotiating group, Draft decision -/CP.6, Capacity-building in countries with economies in transition. 
processes such as the overall multi-donor funded framework of Poverty Reduction Strategy Papers and the Comprehensive Development Framework.

\section{Box 3: Project vs. Programmatic Approach}

While a "project" or "action plan" has specific starting and end dates and a very specific goal, a "programme" is a long-term initiative which provides an overall framework for co-ordinated action and implementation of specific activities. A programme is usually larger in scope and may comprise multiple projects, as well as an overall vision, policy milestones and long-term plans. Due to the considerable challenges associated with implementation of the objectives of the Rio Conventions, many countries have established thematic programmes that recognise the longterm nature of the task and goals to be accomplished. 


\section{Designing and Executing the National Capacity Self-Assessment Process}

This part of the document is meant to assist in identifying participants, consultative mechanisms and procedures for the NCSA process. At each stage, it is important to consider existing structures and initiatives (as well as lessons learned) that can benefit the NCSA process. ${ }^{12}$ In thinking through the range of preparatory issues outlined below, the reader should keep in mind that the NCSA comprises both a needs assessment in the three thematic areas, as well as identification of synergistic and cross-cutting opportunities for capacity building.

\section{Initiating the Self-Assessment Process}

The National GEF Focal Points, as well as the national focal points for the Rio Conventions are likely to play an important role in initiating and facilitating the NCSA process. It is therefore suggested that these focal points meet for some preliminary discussions on how the NCSA process may be implemented. The involvement of high-level committees (e.g. Council of Ministers, State Planning Committee, NCSD) as well as other national co-ordinating mechanisms is also important at this stage and such bodies should be identified for this purpose. Other actors that may also bring important contributions to these initial discussions may include governmental decision-makers that can help to ensure that the process succeeds. An initial dialogue with key non-governmental organisations (NGOs) at this early stage may also bring benefits to the process, while still maintaining full governmental involvement.

\section{Ensuring Participation of Relevant Government Sectors}

It is also important to consider early on how to ensure support and participation of all concerned ministries and agencies. While it will be crucial to involve certain key ministries and agencies, some might not see the relevancy of the NCSA to their mandates. For example, officials from a Ministry of Finance or Economics may have no direct interest in the three Rio Conventions, but may make decisions that have profound implications for the success of related projects or programmes. It is therefore critical to establish dialogue with such key ministries and agencies and make apparent the NCSA's links with sustainable development and the particular interests of each ministry and agency. This will help to ensure that they clearly see the important role they can play in, and the benefits to be gained from, the NCSA process.

A wide range of government ministries and agencies have access to important human and financial resources and can make significant contributions to the NCSA. It is therefore important

\footnotetext{
${ }^{12}$ For example, the NCSA process can inform and influence a country's participation in the final regional and global prepcoms of the World Summit on Sustainable Development (WSSD) that will run until the beginning of June 2002. Completed NCSAs or status reports could also be distributed at the WSSD. Once countries have undertaken a NCSA, it may be of interest to discuss their findings at the regional and global level to identify possible areas for collaboration.
}

A Guide for Self-Assessment of Country Capacity Needs for Global Environmental Management Page 11 
to identify all potential partners within the government (federal, regional and local; ministries, agencies or bodies) who should become involved in the NCSA process. Ministries who have mandates directly related to the three Rio Conventions are most obvious and easiest to identify. There may be others, however, for whom the relationship is not as immediately obvious.

Governmental departments, ministries or agencies which might contribute to the NCSA process, include, inter alia:

- Environment

- Forestry

- Agriculture

- Science and Technology

- Transportation

- Finance or Economics

- Planning

- Education
- Energy

- Natural Resources

- Health

- Foreign Affairs

- Water Affairs

- Minerals and Energy

- Trade and Industry

- Public Works

Raising awareness on the NCSA can be a good start to obtaining such support and participation and can contribute not only to a successful NCSA, but also help to pave the way for further support and participation regarding related future activity. Awareness-raising can include providing information regarding the NCSA, what opportunities the preparation of a NCSA can provide, and the implications and responsibilities it holds for those who will be involved in and affected by the process (and related future activity). The "buy-in" and support of ministries and agencies will be needed to secure necessary human resources and input for the successful preparation of the NCSA.

\section{Identifying and Engaging Non-Governmental Stakeholders}

As is the case with governmental partners, while not all interested and affected parties (hereinafter called stakeholders) will need to be directly involved in the NCSA process, it is nevertheless important to understand who the stakeholders are (within the thematic areas of biodiversity, climate change and desertification/land degradation and across the thematic areas within the broader environmental manage ment and sustainable development context), and to ensure that their perspectives and concerns are taken into account. Involving key stakeholders may also be of practical relevance, since their actions and commitment will likely be essential to the implementation and success of the resulting strategies for capacity building. For example, private-public partnerships can often successfully access resources that are additional to what government can offer and thus provide added value.

Making use of existing structures and initiatives, as suggested earlier, may assist in this step (among others) of the NCSA process. For example, the bottom-up and participatory approach used by CCD National Co-ordinating Bodies (NCBs) charged with the responsibility of supervising the elaboration and implementation of the National Action Progammes (NAPs) for the CCD may already have established a solid foundation for multistakeholder participation in 
preparing the NCSA, or at least for its thematic component addressing desertification/land degradation.

The list of participants in the NCSA process will vary among countries. In most cases, stakeholders will come from the following two major sectors of the country:

\section{- NGO and interest-group representatives:}

These may include consumer, environmental, or other community-based organisations (e.g. women's groups), industry groups and other associations that share a concern about the thematic areas of biodiversity, climate change and desertification/land degradation and the broader environmental management and sustainable development context. These groups often have specific knowledge of certain aspects related to the three thematic areas which will be valuable to include in the NCSA.

\section{- Academic and research-sector interests:}

This group typically includes researchers from major universities as well as representatives of agricultural, forestry, or marine research centres and other sources of scientific/technical information needed for the management of biodiversity, climate change and desertification/land degradation and other efforts within the broader environmental management and sustainable development context.

It is important to develop a thorough understanding of the interests and potential contributions of different stakeholders. This will provide insight into who can be involved, what roles they might be expected to play in the process, how they might become involved, etc. It is equally important to determine what roles each stakeholder would like to play in the NCSA process, and what expectations they have regarding their participation as well as the NCSA in general. Box 4 provides some suggestions concerning such issues.

\section{Selecting Stakeholder Involvement Approaches}

Stakeholder involvement may comprise any or a combination of a range of activities, tools and relationships, such as: two-way communication, advisory boards, stakeholder consultation, partnerships and joint decision-making. While stakeholders can become involved in a multitude of ways, the best stakeholder involvement mechanisms are realistic, practical and visible to all participants. It is also important to determine when the various stakeholders will get involved in the process. Box 5 provides a summary of some stakeholder involvement mechanisms.

\section{Ensuring Successful Stakeholder Participation}

Effective stakeholder involvement will require a high degree of flexibility. If anticipated results with regard to stakeholder involvement are not being generated, if participants are dissatisfied or 


\section{Box 4: Conducting a Stakeholder Analysis}

In order to determine who should possibly be involved or might want to be involved, the following questions can be asked:

- Who is/might be interested in or affected by the thematic area?

- What are their interests and positions?

- Who has information and expertise that might be helpful?

- Who has been/is involved in similar initiatives or planning?

- Who has expressed interest in being involved in similar initiatives/efforts before?

- Who else might be interested in contributing to the NCSA?

A simplified table for categorising stakeholders, which may assist with the stakeholder analysis, is shown below. After identifying stakeholders, their interests, etc., it may be helpful to divide stakeholders into four categories: those who will likely want to participate fully or whose active involvement will determine the credibility of the process; those who would likely play a more limited role; those who likely will wish simply to be kept well informed; and those who will not want to be involved. This categorisation may help with organisational matters.

\begin{tabular}{|c|c|c|c|}
\hline $\begin{array}{c}\text { Who? } \\
\begin{array}{c}\text { Stakeholder } \\
\text { Name }\end{array}\end{array}$ & $\begin{array}{c}\text { What? } \\
\text { Stakeholder } \\
\text { Interests, Position } \\
\text { \& Official Mandate }\end{array}$ & $\begin{array}{c}\text { Weasons for } \\
\text { Inclusion }\end{array}$ & $\begin{array}{c}\text { How? } \\
\text { Possible } \\
\text { Role }\end{array}$ \\
\hline & & & \\
\hline & & & \\
\hline & & & \\
\hline
\end{tabular}


sceptical, or if unforeseen developments have altered the dynamics, the process should be modified. Important questions to consider at the outset of stakeholder involvement in the NCSA process include:

- Has a clear statement of purpose and intentions for stakeholder involvement been provided?

- Has the deadline for completing the NCSA and any stages along the way been clarified?

- Do stakeholders have a clear understanding of what is expected from them? Have stakeholders provided a clear explanation of what they expect?

- Does the knowledge of stakeholders' issues and concerns include an understanding of: (i) who is affected by the thematic area, and (ii) the sectors, interests and/or regions that different stakeholders represent?

\section{Identifying an Appropriate Mechanism for Overall NCSA Co-ordination}

Identifying an appropriate mechanism for the overall co-ordination of the NCSA is a key to its success. Often broader based consultation mechanisms, such as NCSDs, have already been established and may provide an ideal "platform" to co-ordinate the NCSA. Such consultative mechanisms can also help to facilitate the identification of potential participants for the NCSA process. Other mechanisms which may exist in countries and may fulfil the overall co-ordinating function include, for example:

- $\quad$ National Environmental Councils

- $\quad$ National GEF Co-ordination Mechanisms

- $\quad$ National Capacity 21 Committees

Each country would need to decide which high-level body is the most appropriate to provide the overall leadership required to execute the NCSA and to ensure adequate follow-up action. In certain countries, where an overall co-ordinating mechanism is not in place, the execution of the NCSA may actually provide an opportunity to establish such a mechanism.

\section{Identifying Mechanisms for Undertaking the Thematic Assessments}

It is also important to identify consultative mechanisms for preparing assessments of each thematic area, i.e. biodiversity, climate change and desertification/land degradation. ${ }^{13}$ In many countries, such specialised consultative mechanisms have already been established as part of national development and implementation of project and programmes related to the implementation of the three Rio Conventions.

${ }^{13}$ Alternatively, countries, for example, might decide that multithematic working groups charged with examining the economic, scientific or legal capacity constraints associated with implementing the Rio Conventions is a more appropriate way to approach the problem. 


\begin{tabular}{|c|c|c|c|}
\hline \multicolumn{4}{|c|}{ Box 5: Stakeholder Involvement Approaches } \\
\hline & Definition & Examples & Advantages \\
\hline $\begin{array}{l}\text { Two-way } \\
\text { Communication }\end{array}$ & $\begin{array}{l}\text { Basic information } \\
\text { collection and timely } \\
\text { response to public } \\
\text { questions or concerns. }\end{array}$ & $\begin{array}{l}\text { Survey, questionnaire, } \\
\text { Internet discussion } \\
\text { groups, workshops, } \\
\text { discussion papers, } \\
\text { feedback lines. }\end{array}$ & $\begin{array}{l}\text { Opportunity to interact } \\
\text { with stakeholders and } \\
\text { adapt assessment to } \\
\text { address specific } \\
\text { concerns more } \\
\text { directly. }\end{array}$ \\
\hline Advisory Bodies & $\begin{array}{l}\text { A short-term body with } \\
\text { a mandate to gather } \\
\text { expert opinion on an } \\
\text { issue or bring together } \\
\text { different types of } \\
\text { expertise. }\end{array}$ & $\begin{array}{l}\text { Scientific advisory } \\
\text { boards, expert } \\
\text { advisory panels, } \\
\text { programme advisory } \\
\text { committees. }\end{array}$ & $\begin{array}{l}\text { Provide informed, } \\
\text { multistakeholder } \\
\text { insights and } \\
\text { recommendations; } \\
\text { forum for public to } \\
\text { influence decision. }\end{array}$ \\
\hline $\begin{array}{l}\text { Stakeholder } \\
\text { Consultation }\end{array}$ & $\begin{array}{l}\text { A facilitated process } \\
\text { for fostering dialogue } \\
\text { and gathering public } \\
\text { input. Stakeholders } \\
\text { can contribute to } \\
\text { process design and } \\
\text { implementation. }\end{array}$ & $\begin{array}{l}\text { Consultation meetings, } \\
\text { teleconferencing, } \\
\text { focus groups, } \\
\text { community meetings. }\end{array}$ & $\begin{array}{l}\text { Involvement of } \\
\text { professional facilitators } \\
\text { to lead discussion and } \\
\text { seek common ground } \\
\text { can build trust and } \\
\text { demonstrate } \\
\text { government's } \\
\text { commitment to } \\
\text { openness and } \\
\text { transparency. }\end{array}$ \\
\hline Partnerships & $\begin{array}{l}\text { A participatory process } \\
\text { in which two or more } \\
\text { parties accept joint } \\
\text { responsibility for } \\
\text { various aspects of the } \\
\text { process. }\end{array}$ & $\begin{array}{l}\text { Co-hosting workshops, } \\
\text { co-production of } \\
\text { educational materials, } \\
\text { joint delivery of a } \\
\text { service. }\end{array}$ & $\begin{array}{l}\text { Facilitators help to } \\
\text { ensure that all voices } \\
\text { are heard. } \\
\text { Representatives } \\
\text { of participating } \\
\text { organisations share } \\
\text { information with their } \\
\text { members and act on } \\
\text { their behalf. }\end{array}$ \\
\hline $\begin{array}{l}\text { Joint Decision- } \\
\text { making }\end{array}$ & $\begin{array}{l}\text { An approach in which } \\
\text { two or more parties } \\
\text { make decisions about } \\
\text { a policy, programme } \\
\text { and/or process, and } \\
\text { share responsibility } \\
\text { and accountability for } \\
\text { the outcome. }\end{array}$ & $\begin{array}{l}\text { Joint working group for } \\
\text { drafting policy } \\
\text { guidance documents, } \\
\text { multistakeholder board } \\
\text { of directors, co- } \\
\text { sponsored } \\
\text { programmes, round- } \\
\text { tables, consensus- } \\
\text { building. }\end{array}$ & $\begin{array}{l}\text { Key stakeholders } \\
\text { usually become } \\
\text { involved at an early } \\
\text { stage, and share } \\
\text { ownership of the } \\
\text { process and outcome. }\end{array}$ \\
\hline
\end{tabular}

A Guide for Self-Assessment of Country Capacity Needs for Global Environmental Management Page 16 
Existing specialised mechanisms may include, for example:

- $\quad$ National Biodiversity Planning Committees

- Interministerial Commissions on Biological Diversity

- National or Inter-agency Committees on Climate Change

- $\quad$ Climate Change Country Teams

- $\quad$ National Desertification Commissions

- $\quad$ National Co-ordinating Bodies/National Committees for CCD

- Inter-ministerial Committees on Environment

- $\quad$ NAP Co-ordinating Committees

Reviewing and making use of these mechanisms, if in place, may be a useful approach to organising the thematic assessment components of the NCSA. Indeed, such mechanisms or bodies should be utilised to the fullest extent possible. Involving specialised mechanisms will also help to ensure that the NCSA process is owned by a larger number of organisations and individuals and that specialised expertise is available for the assessment process.

\section{Agreeing on the NCSA Process}

It is suggested that agreement on all operational aspects of the NCSA process is reached as early as possible, to ensure that each participant is clear about the process and its intentions. Experience gained through related projects has shown that a national planning workshop which involves all affected and interested parties can result in an agreed workplan which is endorsed and supported by all those who will contribute to NCSA (see Box 6). It may also be appropriate to identify a neutral facilitator to assist with the process, ensure fluidity and, where necessary, remedy any conflict.

\section{Developing Terms of Reference}

Developing and agreeing on Terms of Reference which comprise brief, but sufficiently descriptive operational details on various administrative and organisational issues pertaining to the NCSA process is considered important. The Terms of Reference should include a workplan that sets out the details for the NCSA process, such as milestones, sequence of events, timelines and expected outputs. Key decisions will also need to be made and documented on relevant resources allocations, sequence of activities, responsibilities; and monitoring procedures to ensure effective and timely delivery of outputs. 


\section{Box 6: Holding a National NCSA Planning Workshop}

Holding a National NCSA Planning Workshop early in the process can help to ensure that the NCSA process is accepted as a national activity that requires input from all affected and interested parties. A preliminary step will be to identify and agree on an agenda and background documents for agenda items. By the end of the workshop, agreement should be reached on:

- the objectives and anticipated benefits of preparing the NCSA;

- the selection of the overall co-ordinating mechanism;

- the need for, and establishment of, working parties responsible for developing the thematic assessments, if existing consultation mechanisms are not in place;

- a workplan for preparation of the NCSA;

- intermediate and final outputs; and

- a timeframe for completion of the NCSA.

Participants of the National Planning Workshop should include representatives of all interested national, regional and local ministries/agencies, universities and research institutes, industrial and professional organisations, labour organisations, and environmental, consumer and other interested community-based groups. In particular, the representatives of the various national ministries should be high-level officials with sufficient authority to ensure the required input of various ministries in the NCSA process. Countries may also consider inviting representatives of international and bi-lateral technical co-operation agencies and organisations which have interests and programmes related to the thematic areas and which are present in the country. 
This part of the Guide introduces a suggested four step process for undertaking thematic assessments for the three areas of biodiversity, climate change and desertification/land degradation respectively, including identification of opportunities for thematic capacity building. The following part (Part 6) provides suggestions to identify opportunities for capacity building that cut across the three thematic areas. ${ }^{14}$ Suggested activities in Parts 5 and 6, however, do not necessarily need to be implemented in sequence. For example, it may be possible to first identify capacity building opportunities across the thematic areas followed by the identification of capacity building opportunities within the thematic areas. With any approach, it is worthwhile considering possible commonalities or synergies among the three thematic areas during the preparation of thematic assessments. Also, in undertaking the thematic assessments, provisions and decisions of the relevant conventions should be kept in mind.

\subsection{Understanding the Baseline Situation for Each Thematic Area: Preparing Thematic Profiles/Situation Analyses}

In order to develop specific opportunities for capacity building within the three thematic areas of biodiversity, climate change and desertification/land degradation, a good understanding of the baseline situation for each of the respective area is essential. The availability of a thematic profile/situation analysis can provide insight and guidance into major challenges and opportunities for future capacity building interventions. It is with this information in hand that priorities can be identified (or confirmed) and related capacity constraints and opportunities for capacity building determined.

Many countries have already prepared a variety of reports related to the thematic areas of biodiversity, climate change and desertification/land degradation. For example, under the CBD, countries have prepared National Biodiversity Strategies or Action Plans; under the UNFCCC, countries have prepared National Communications; and under the CCD, participating countries are encouraged to prepare National Reports. At this stage, it would be useful to "take stock" of these reports. Some national reports which may assist in preparing the NCSA are presented in Box 7 below. Based on a review of all relevant information, a thematic profile/situation analysis can be prepared to serve as a basis for identifying existing strengths as well as weaknesses and thus facilitate an effective priority setting process. ${ }^{15}$

\footnotetext{
${ }^{14}$ One possible approach to the NCSA is to envisage it the context of a traditional planning framework. That is, seeing the NCSA process as comprising at least three main phases: (i) undertaking preparatory tasks for the assessment; (ii) conducting and drafting the assessment; and (iii) monitoring and updating the results of the assessment.

15 The opportunity to base the NCSA on the outputs of thematic capacity needs-assessments that have already been carried out in the framework of the Rio Conventions will vary from country to country and will subsequently influence which activities are required for undertaking the NCSA.
} 


\section{Box 7: Existing National Reports which ma y Inform the Preparation of Thematic Profiles}

Biodiversity

- National Biodiversity Assessments, Strategies and Action Plans

- Forestry Assessments, Strategies and Action Plans

\section{Climate change}

- UNFCCC National Communications

- Climate Change Assessments, Strategies and Action Plans

\section{Desertification/Land degradation}

- National Action Programmes to Combat Desertification (NAPs)

- National Reports on the Implementation of the CCD

\section{Cross-cutting and miscellaneous}

- National Environmental Action Plans (NEAPs)

- National Sustainable Development Strategies

- National Agenda 21 Reports

- Capacity 21 Programme Reports

- State of the Environment Reports

- National Conservation Strategies

- Biosafety Frameworks

- Stockholm Convention (Persistent Organic Pollutants) Implementation Plans

- UNCED National Reports

- Environmental planning documents

- Capacity needs assessments

- Sector studies

Preparing a separate profile for each of the thematic areas is considered to be important to obtain a clear understanding of each thematic area. ${ }^{16}$ While various options exist regarding the magnitude of thematic profiles and the process selected for preparing the profiles ${ }^{17}$, it is important that all interested and affected parties have an opportunity to contribute to the preparation of the profiles. If existing consultative mechanisms for the three thematic areas are not in place, the preparation of a profile can provide a starting point for co-ordination and collaboration. Because the profile can serve as a tool for revealing existing challenges and opportunities for capacity building, and because it can bring together many of the key actors, preparing a thematic profile can also provide an opportunity for strategic dialogue and an opportune basis for determining potential follow-up activities.

In some cases, analysis of certain aspects may be quite challenging and resource intensive. An initial scoping and priority setting exercise might be helpful to define topics that could be adequately addressed.

\footnotetext{
16 Another approach countries may wish to consider involves preparing one profile rather than three thematic profiles. The first part might contain a general framework (baseline) that concerns all three thematic areas, while the second part might focus on possible cross-cutting issues.

${ }^{17}$ For example, some countries may find it more effective to focus the NCSA on developing an integrative approach to global environmental management and moving from there to thematic assessments, while others countries may find the opposite approach more effective.
} 


\section{Box 8: Suggested Content of a Thematic Profile}

While the content of each thematic profile will differ, it should answer a number of basic questions. Such questions can include:

- What are the relevant legal instruments, policies and/or non-regulatory mechanisms? Are they effective and do any overlap, gaps or inconsistencies exist?

- What are the responsibilities and relevant activities of ministries, agencies and other governmental institutions? Are these activities well co-ordinated and complementary?

- What are the respective roles and contribution of industry, public interest groups and bodies in the research sector? Which organisations have major interest and programmes in the relevant subject area?

- What relevant information and databases exist, where are they located and who has access to them? Are all relevant data needs well addressed? What are the major gaps?

- Which relevant projects have been implemented and what are the impacts of these projects, as well as lessons learned?

- What kinds of capacity development projects and activities have been undertaken? What were the short-term and long-term impacts of those projects and activities?

- What relevant technical capacity exists and is this infrastructure available and sufficient to address the objectives of the respective area?

- What is the level of awareness and understanding within government and the public concerning the thematic area?

- What human resources are available, and through which organisations, to work on the respective thematic area?

- What training and human resource programmes exist and what do they offer?

- What financial resources might be available at the national level for action plans concerning the thematic area?

- Has there been any monitoring and evaluation of capacity development projects and activities during or after their execution? How has the country measured their success or effectiveness?

- Do individuals have an incentive to acquire new skills and technical capacity related to the thematic area? Do they have sufficient opportunity to do so?

- Are individuals in contact and exchanging knowledge and experiences with appropriate peers? Are their barriers to communication within and across relevant institutions focused on the thematic area?

- Does any untapped capacity exist or is there capacity that could be redeploy ed to better effect? Is there capacity in danger of being lost?

- Are capacity development efforts sufficiently linked to existing or future legal, regulatory, or institutional requirements and responsibilities? Has capacity built in the past proved to be sustainable over the medium- and long-term? 


\section{Gathering and Analysing Information}

Preparing a thematic profile could be divided into two parts: information collection and information analysis. Making use of existing national reports, where appropriate, could serve as a good starting point for this analysis. In fact, if such reports provide all relevant information (see Box 7 above), no additional work may be required (other than reviewing and synthesising information). Information for the thematic profiles could also be obtained through: other literature reviews, questionnaires, personal communications, interviews or group discussions, site visits, etc. It may also be useful to assess the degree of success achieved in past capacity building efforts and, where applicable, explore possible reasons for why certain efforts have not been sustainable. Analysing information entails reviewing existing and newly gathered information and identifying gaps/weaknesses and strengths. It may be helpful to ask: "What do we have?" followed by "What's inadequate?" and "What's missing?" Box 8 provides some suggestions regarding the content of a thematic profile.

\subsection{Identifying, Confirming or Reviewing Priority Issues within Each Thematic Area}

Upon reviewing the thematic profiles, relevant strengths and gaps should become apparent. The matrix provided in Box 9 is meant to assist a working group to identify, confirm or review priority issues within each thematic area. ${ }^{18}$ The three reference lists provided in Annex B (one for climate change, one for biodiversity and one for land degradation) could serve as a potential starting point for these exercises. The three lists outline what issues may be particularly relevant to each thematic area. Reviewing the information contained in the profiles against these issues may help to highlight issues that are particularly important within the country's unique context. Setting or confirming priority issues will also help to provide focus for the identification of capacity constraints and ultimately future capacity building projects.

In order to conduct a transparent priority setting exercise, it may be helpful to use simple decision criteria against which the various issues can be evaluated and prioritised. One approach to setting priorities is to make use of a "prioritisation matrix". Box 9 presents this matrix with some examples of priority issues for the thematic area of biodiversity. This priority setting exercise (or priority confirmation or review) should result in a manageable number of issues which are of paramount importance and which may require capacity building. ${ }^{19}$

\footnotetext{
${ }^{18}$ It is understood that many countries have undertaken processes to identify priorities. In which cases, countries may wish to take this opportunity to confirm or review their priorities.

19 With regard to funding, setting priorities is of particular importance as both national and external funders would likely only be able to offer support for a limited number of issues.
} 


\section{Box 9: Issue Prioritisation Matrix}

Ranking issues against the following criteria will allow a simple comparison of the relative importance of each and should thereby facilitate further group discussion on setting, confirming or reviewing priorities. Such a tool, however, should not be seen as an end in itself. It is first and foremost an evaluative tool. Simply adding values assigned to each issue will not take into account the different weighting assigned to particular criteria.

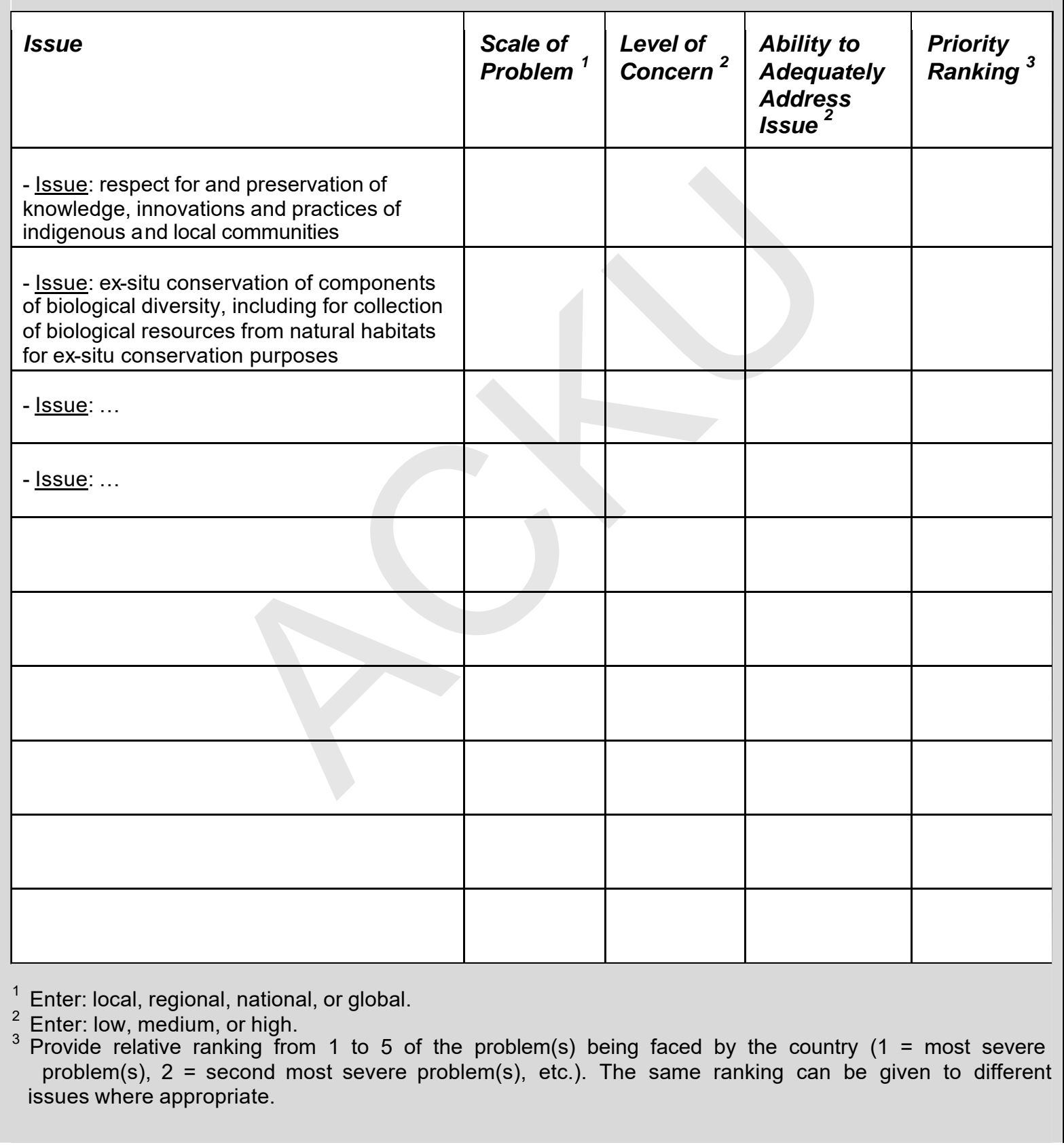

A Guide for Self-Assessment of Country Capacity Needs for Global Environmental Management Page 23 


\subsection{Identifying Capacity Constraints for Priority Issues for Each Thematic Area}

Once a number of priority issues have been determined, relevant capacity constraints can be identified, within each thematic area. In this context, "capacity constraints" can be defined as something that prevents effectively addressing issues identified above. In order to efficiently and effectively identify and assess capacity constraints, it is important to explore and agree upon the "tools" to be used. ${ }^{20}$ While outlining the numerous tools which can be used is beyond the scope of this document, a standard approach is discussed below. With any approach, the guiding question should always be, "What specific problems are preventing an adequate response to the priority issues?"

\section{Developing a Root Cause Analysis}

One approach for identifying capacity constraints is to build on the information collected in the thematic profiles by thinking through further the reasons for the existence of identified gaps or weaknesses. This involves identifying the negative aspects of an existing situation and establishing the "cause and effect" relationships between the problems that exist.

A "problem tree", which represents a comprehensive picture of the existing challenges and problems that require attention, is a useful tool that can be used for developing a root cause analysis. This involves identifying, for each priority issue, key problems (or causes and effects). A first step may be to identify a "starter" problem for the priority issue followed by a second problem related to it. Problems can then be identified for a number of additional levels. It is possible to work upwards and well as downwards to help with the identification. Once a considerable number of problems have been identified, the items can be reviewed and rearranged as necessary.

Developing this "root cause analysis" can be concluded when participants feel that the problems and their cause and effect relationships have been adequately explored. ${ }^{21}$ Resulting from this exercise would be a list of problems (including the identification of focal or central problems) relevant to the thematic area. These problems are essentially capacity constraints. These can then be grouped into categories along the concepts of individual, institutional and systemic capacity constraints. ${ }^{22}$ It is important to assess and group capacity constraints according to these three levels of capacity constraints, as the level at which the capacity constraint occurs will influence the type of capacity building required. The concept of systemic, institutional and individual levels of capacity constraints and guiding questions for identifying these are outlined below. ${ }^{23} \mathrm{~A}$

\footnotetext{
20 Various tools can be used in this capacity, including: Logical Framework Approach's (LFA) "Problem and Objective Trees", the SWOT Analysis, Force Field Analysis, Fishbone or Ishikawa Diagram, etc.

${ }^{21}$ While capacity constraints at the "root level", such as broader public management and migration, will be difficult to address, it is nevertheless import to obtain an understating of such constraints .

22 Additionally, it might be useful to separate the short-term capacity constraints from the long-term capacity constraints.

${ }^{23}$ GEF-UNDP. Capacity Development Initiative.
} 
matrix which can help to organise the capacity constraints identified is presented in Box 10 below.

\section{Assessing Capacity Constraints at the Systemic Level}

Capacity building at the systemic level emphasises the overall policy framework in which individuals and organisations operate and interact with the external environment, as well as the formal and informal relationships of institutions. Guiding questions include:

- Policy framework: Is the overall policy environment conducive?

- Legal and regulatory framework: Is the appropriate legislation in place and are these laws effectively enforced? (These may be both formal and informal, such as cultural mores)

- Management accountability framework: Are institutional responsibilities clearly defined and are responsible institutions held publicly accountable?

- Economic framework: Do markets function effectively and efficiently?

- Systems level resources: Are the required human, financial and information resources available? (These may be in any or all of national and local government, private sector, and civil society - including NGO's)

- Processes and relationships: Do the different institutions and processes interact and work together effectively? (Including national and local government, private sector, and civil society)

\section{Assessing Capacity Constraints at the Institutional Level}

Capacity building at the institutional level focuses on the overall organisational performance and functioning capabilities, as well as the ability of an organisation to adapt to change. It aims to develop the institution as a total system, including individuals, groups and the organisation itself. Guiding questions include:

- Mission/strategic management: Do the institutions have clearly defined and understood missions and mandates?

- Culture/structure/competencies: Are the institutions effectively structured and managed?

- Processes: Do institutional processes such as planning, quality management, monitoring and evaluation, work effectively?

- Human resources: Are the human resources adequate, sufficiently skilled, and appropriately deployed?

- Financial resources: Are financial resources managed effectively and allocated appropriately to enable effective operation?

- Information resources: Is required information available and effectively distributed and managed?

- Infrastructure: Are material requirements such as buildings, offices, vehicles, computers, allocated appropriately and managed effectively? 


\section{Box 10: Capacity Constraints Matrix}

Once capacity constraints are identified, they can be charted below under the appropriate categories of individual, institutional and systemic capacity constraints (it is possible that a priority issue pertains to only one or two of the three levels of capacity constraints). This matrix may help to organise the categorisation of capacity constraints identified which, in turn, may facilitate the identification of related opportunities for capacity building.

\begin{tabular}{|l|l|l|l|}
\hline \multicolumn{1}{|c|}{ Priority Issues } & $\begin{array}{c}\text { Individual } \\
\text { Capacity Constraints }\end{array}$ & $\begin{array}{c}\text { Institutional } \\
\text { Capacity Constraints }\end{array}$ & $\begin{array}{c}\text { Systemic } \\
\text { Capacity Constraints }\end{array}$ \\
\hline $\begin{array}{l}\text { - Issue 1: development } \\
\text { of economically and } \\
\text { socially sound measures } \\
\text { that act as incentives for } \\
\text { the conservation and } \\
\text { sustainable use of } \\
\text { components of biological } \\
\text { diversity }\end{array}$ & $-\ldots$ & $\ldots$ & $\ldots$ \\
\hline $\begin{array}{l}\text { - Issue 2: preservation } \\
\text { of traditional knowledge } \\
\text { and coping mechanisms }\end{array}$ & & & \\
\hline - Issue 3: ... & & & \\
\hline - Issue 4: ... & & & \\
\hline & & & \\
\hline \hline $\begin{array}{l}\text { Common } \\
\text { Constraints within } \\
\text { Thematic Area }\end{array}$ & & & \\
\hline
\end{tabular}

A Guide for Self-Assessment of Country Capacity Needs for Global Environmental Management 


\section{Assessing Capacity Constraints at the Individual Level}

Capacity building at the individual level refers to the process of changing attitudes and behaviours-imparting knowledge and developing skills while maximising the benefits of participation, knowledge exchange and ownership. Guiding questions include:

- Job requirements and skill levels: Are jobs correctly defined and are the required skills available?

- Training/retraining: Is the appropriate learning taking place?

- Career progression: Are individuals able to advance and develop professionally?

- Accountability/ethics: Is responsibility effectively delegated and are individuals held accountable?

- Access to information: Is there adequate access to needed information?

- Personal/professional networking: Are individuals in contact and exchanging knowledge with appropriate peers?

- Performance/conduct: Is performance effectively measured?

- Incentives/security: Are these sufficient to promote excellence?

- Values, integrity and attitudes: Are these in place and maintained?

- Morale and motivation: Are these adequately maintained?

- Work redeployment and job sharing: Are there alternatives to the existing arrangements?

- Inter-relationships and team work: Do individuals interact effectively and form functional teams?

- Interdependencies: Are there appropriate levels of interdependence?

- Communication skills: Are these effective?

\subsection{Identifying Opportunities for Capacity Building to Address the Identified Capacity Constraints for Each Thematic Area}

Using the suggestions presented in Box 10 - categorising each capacity constraint identified as either individual, institutional or systemic - may provide direction for identifying possible opportunities for building the capacity needed. It may also be helpful to categorise the type of capacity building required to further define the opportunity for capacity building. Capacity building opportunities can generally be categorised as:

- creating new capacity;

- moblising or redeploying existing capacity; and

- enhancing existing capacities.

This analysis could result in some concrete ideas for capacity building projects and the specific objectives these projects would aim to accomplish. It may be of value to also identify particular project "areas" based on identified opportunities for capacity building. To be most effective, capacity building efforts should be linked to concrete investment and sectoral activities. 


\section{Identification of Bottlenecks}

Identifying capacity bottlenecks can help to ensure that capacity building opportunities selected will provide maximum return for the investment made. Capacity bottlenecks are areas of potential capacity building where the elimination of one capacity constraint will mobilise various existing capacities towards achieving the desired goal. For example, an institution may have skilled staff, however, such staff may not be adequately deployed. Ensuring that the staff are working in the appropriate areas (e.g. through the development of an effective workplan), rather than retraining the staff, can produce great impact for minimal effort. Similarly, it may be helpful to set priorities at various levels. This could include prioritising issues, capacity constraints and opportunities for capacity building. 
Part 6 of this Guide provides suggestions towards identifying synergies for capacity building under the three thematic areas which can -at the same time - address needs within the broader global environmental management and sustainable development context. Synergy can be defined as "a combined effect...that exceeds the sum of individual effects". ${ }^{24}$ Identifying cross-cutting synergies regarding capacity building needs under the Rio Conventions and environmental management in general can therefore be an effective way to ensure effectiveness and efficiency.

An assessment of guidance from the three Rio Conventions shows a notable similarity across the conventions. ${ }^{25}$ For example, education and public awareness are identified as needs of all three conventions. Identification of root causes of loss of biological diversity or loss of soil fertility require overlapping skills. Similarly, adapting to climate change or to drought could also require similar response patterns. Hence any strategy to address capacity needs should explore these cross-convention synergies. ${ }^{26}$ This is especially relevant for the GEF, which is the financial mechanism for both the biodiversity and climate change conventions, and is mandated by its Instrument to support activities to combat desertification/land degradation. Moreover, the CCD specifically mandates co-ordination with the CBD and UNFCCC, including the conduct of joint programmes (Article 8). Box 11 presents an illustrative comparison of data needs across the conventions (Annex $\mathrm{C}$ presents a summary of the various overlapping requirements of the Parties to the Rio Conventions).

The linkages between the thematic areas provide important opportunities. Through a greater understanding of the commonalities and overlaps between the conventions from a national perspective, a co-ordinated and harmonised implementation approach at the local, national and international levels can be facilitated, where feasible. Such an approach may reduce costs, relieve the burden of multiple reporting, and in general can be expected to produce greater effectiveness and efficiency.

\footnotetext{
${ }^{24}$ Concise Oxford Dictionary, 7th edition.

${ }^{25}$ GEF, (GEF/C.17/6/Rev.1), Elements of Strategic Collaboration and a Framework for GEF Action for Capacity Building for the Global Environment, Global Environmental Facility.

${ }^{26}$ In light of the recommendations adopted at the XIX Session of the United Nations General Assembly (UNGASS) of promoting synergies among the Rio Convention, the clearing-house mechanism of the CBD in conjunction with the CCD and the UNFCCC, has initiated a project to promote joint harmonised approaches in the exchange and dissemination of biodiversity-related information. One of the first steps has included the establishment of a list-serv and a joint Internet webpage for the three Rio Conventions with the aim to contribute to the active exchange and discussion of collaborative arrangements in the information management field (UNEP/CBD/QR/3, 20 November 1998).
} 


\section{Box 11: Illustrative Comparison of Data Needs Across the Three Conventions}

\begin{tabular}{|c|c|c|c|}
\hline Core Data Set Needs & Biodiversity & $\begin{array}{l}\text { Climate } \\
\text { Change }\end{array}$ & $\begin{array}{c}\text { Desertification } \\
\text { Land } \\
\text { Degradation }\end{array}$ \\
\hline Land use (by type) & i & i & i \\
\hline Vegetation (by type) & i & i & i \\
\hline Forests (by type, condition, density) & 1 & i & \\
\hline Forest production and export information & $\mathrm{i}$ & $\mathrm{i}$ & \\
\hline Forest tenure/land tenure & $\mathrm{i}$ & & $\mathrm{i}$ \\
\hline Solis (by type) & i & i & $\mathrm{i}$ \\
\hline Agriculture (by type) & i & i & i \\
\hline Rice cultivation & & i & \\
\hline Fertilizer use & & i & \\
\hline Livestock census & $i$ & i & i \\
\hline Wetlands & i & i & \\
\hline Oceans & 1 & - & \\
\hline Climate (temperature, precipitation, etc.) & i & i & i \\
\hline Topography (elevation, slope, aspect) & 1 & & $\mathrm{i}$ \\
\hline $\begin{array}{l}\text { Surface hydrology (lakes, rivers, } \\
\text { streams) }\end{array}$ & & & i \\
\hline Estimate of areas' risk of desertification & 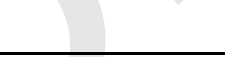 & & $\mathrm{i}$ \\
\hline $\begin{array}{l}\text { Flora and fauna (species type and } \\
\text { density information) }\end{array}$ & i & & \\
\hline Endangered species habitat & i & & \\
\hline Protected areas (by type and condition) & $\mathrm{i}$ & & \\
\hline Human settlements & $\mathrm{i}$ & $\mathrm{i}$ & $\mathrm{i}$ \\
\hline Indigenous peoples homelands & $\mathrm{i}$ & & $\mathrm{i}$ \\
\hline Population (count and density) & i & i & I \\
\hline Roads & $\mathrm{i}$ & $\mathrm{i}$ & $\mathrm{i}$ \\
\hline $\begin{array}{l}\text { Other infrastructure (transmission lines, } \\
\text { etc.) }\end{array}$ & i & $\mathrm{i}$ & i \\
\hline Power transmission lines & i & i & \\
\hline Industrial activities & i & i & \\
\hline $\begin{array}{l}\text { Power generation facilities (by type, } \\
\text { capacity) }\end{array}$ & i & i & \\
\hline
\end{tabular}

Source: Synergies in National Implementation: The Rio Agreements. UNDP.

A Guide for Self-Assessment of Country Capacity Needs for Global Environmental Management 
In order to identify concrete opportunities for capacity building, it may be helpful to develop a table outlining the various areas of cross-cutting capacity constraints and corresponding opportunities for capacity building which cut across the three thematic areas (see Box 12 for an example of this concept).

A useful starting point might be to consider the following indicative listing of cross-cutting capacity constraints. They are considered to be of exemplary nature and countries are encouraged to identify those areas, as well as others, which are considered of greatest importance and relevance. $^{27}$

- awareness and exchange of information;

- national policy, legal and regulatory framework;

- institutional mandates, co-ordination and processes for interaction and co-operation between all stakeholders;

- information management, monitoring and observation;

- moblisation of science in support of decision-making;

- financial resources and technology transfer;

- incentive systems and market instruments;

- negotiation;

- co-operation and networking with regions;

- institutional management and performance; and

- individual skills and motivation.

${ }^{27}$ It should be kept in mind that the areas of potential capacity constraints listed are not mutually exclusive or unrelated to each other. This list has been prepared by CDI based on identified country-level cross-cutting capacity needs. GEF-UNDP, October 2000, Country Capacity Development Needs and Priorities: A Synthesis. 


\section{Box 12: Identifying Capacity Constraints and Opportunities for Integrated Capacity Building}

For each area of cross-cutting capacity constraints listed in the first column, enter related details under the corresponding thematic areas to indicate what, if any, are the related opportunities for capacity building within each thematic area (analysis can take place at various levels: countries can look at capacity constraints and/or opportunities fr capacity building already identified). Looking across each row, it should then be possible to determine where opportunities exist for cross-cutting capacity building. These cross-cutting opportunities can be recorded in the last column.

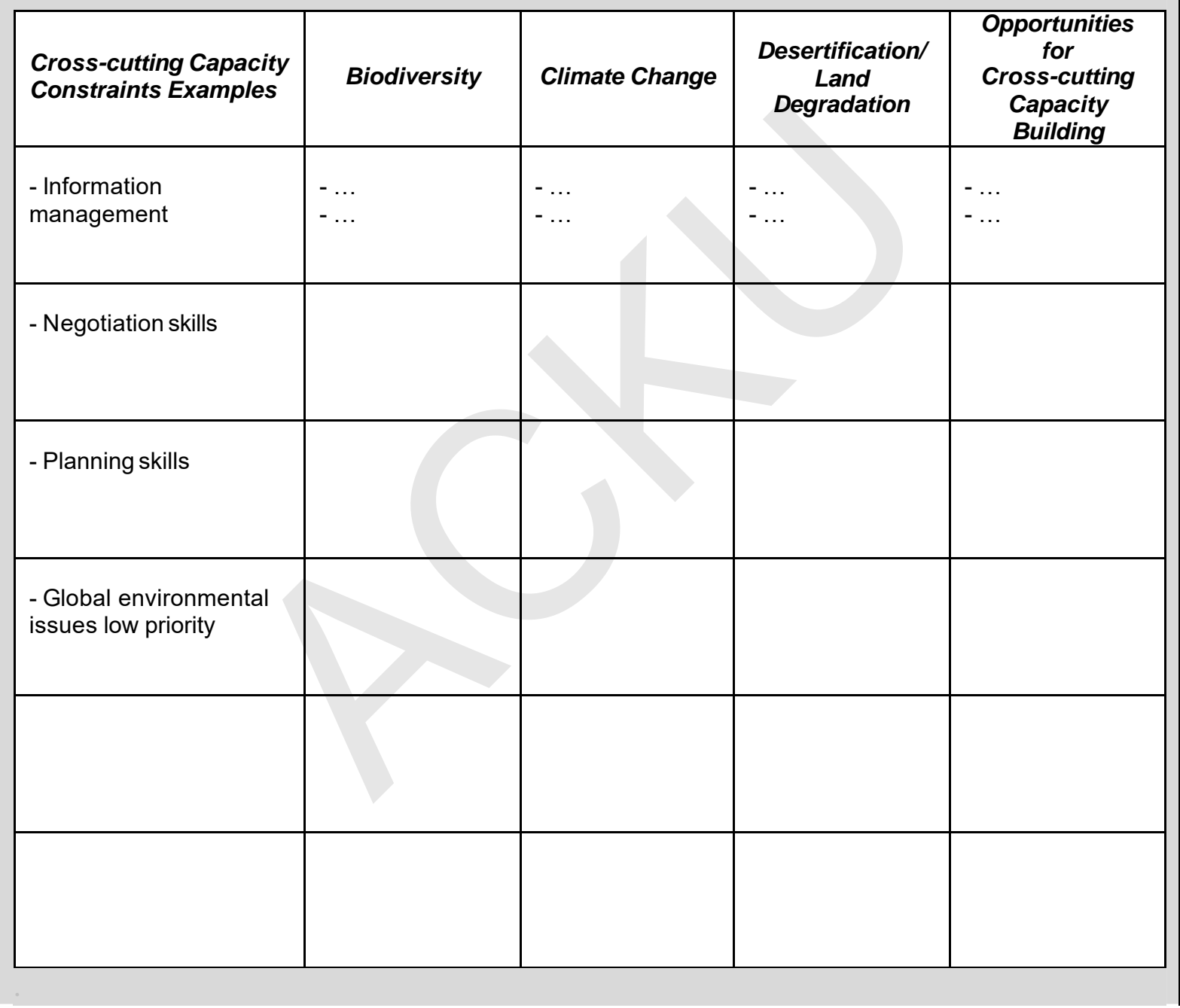

A Guide for Self-Assessment of Country Capacity Needs for Global Environmental Management 


\section{PreParation OF a National CaPaCity Self-ASSESSMENT DoCUMENT AND TAKING NEXT STEPS}

\section{Preparing the NCSA Document}

Taking into consideration the results from the previous assessment phase, it should be possible to synthesise the results into a single concise document, the NCSA. This document can serve as an important tool to brief national decision-makers as well as external funding agencies about specific capacity needs to protect the global environment. Box 13 provides some suggestions on how the structure of the NCSA document may look and some options which countries may wish to pursue.

\section{Moving from the NCSA to Strategy Development}

Based on the capacity constraints and opportunities for capacity building identified, countries may wish to consider the option to start developing a strategy for capacity building to protect the global environment. The strategy may comprise a goal, specific objectives to be achieved and courses of action or concrete projects. A useful approach may be to develop a strategy for each thematic area as well as a cross-cutting strategy.

As discussed earlier, it is important to incorporate follow-up action, including any GEF-specific action plans within the national environmental management and sustainable development context. The following are some approaches that may be taken to achieve this goal, which are based on discussions at an expert meeting on synergies in national implementation of the Rio agreements. $^{28}$

- Develop a new umbrella/master plan that incorporates all conventions: While this option allows for greater harmonisation of the conventions, it may lead to conflicts with existing national development plans. It also requires substantial new resources for planning implementation and is likely to burden country planning capacity. However, in countries without an existing national plan, this umbrella/master plan approach may be desirable.

- Develop a mechanism to integrate planning associated with the conventions into existing national plans and planning framework: This option has the advantage of producing a synergy between convention planning and other existing national programmes and plans. For example, components of a plan to implement the CBD might include problems such as loss of biodiversity through monoculture, forest

\footnotetext{
${ }^{28}$ These options were developed by the Expert Meeting on Synergies, organised by UNDP and funded by the Governments of Israel, Japan, Norway and Denmark. Synergies in National Implementation: The Rio Agreements. UNDP.
} 


\section{Box 13: Possible Table of Contents of a National Capacity Self-Assessment}

\section{Executive Summary}

- Summary of NCSA including proposed next steps

\section{Introduction and Background}

- Rationale and context of the NCSA

- Overview of participation and preparation process

\section{Identified Thematic Priority Issues}

- Summary overview of the existing situation and identified, confirmed or reviewed priority issues for climate change, biodiversity and desertification/land degradation (thematic profiles to be included as Annex)

\section{Summary of Capacity Constraints and Opportunities for Capacity Building in the Three Thematic Areas}

- Detailed description of capacity constraints for the three thematic areas

- Presentation of thematic project opportunities identified for building capacity

\section{Opportunities for Synergistic and Cross-cutting Capacity Building Approaches ana} Projects

- Presentation of opportunities for synergistic and cross-cutting capacity building approaches and projects

\section{Elements of a Strategy for Capacity Building to Protect the Global Environment (Optional)}

- Presentation of strategy for capacity building and sustaining the capacity developed, both within and across the thematic areas, including, where applicable, overall goals, specific objectives and elements of an action plan

\section{Proposed Next Steps and Follow-up (Optional)}

- Brief description of next steps that need to be taken in order to be in a position to begin developing and/or implementing proposed strategies (this section should clarify who is expected to do what)

\section{Monitoring and Evaluation (Optional)}

- Brief outline of monitoring and evaluation procedures to ensure effective and timely implementation of strategy/action plan.

\section{Annexes}

- Terms of Reference for NCSA process and contact details for participants

- Thematic Situation Analyses/Profiles 
clearing, misuse of pesticides, and solutions such as mixed cropping, agroforestry, and integrated pest management. These elements feed directly into the agricultural sector of the existing national development plan, thus ensuring that the two plans are integrated and harmonised. Integrated planning also has the advantage of making use of existing planning structures, thus producing cost effectiveness and planning efficiencies.

- Develop a strategy based on an effective existing thematic strategy, project or programme: If an effective project or programme already exists for one of the three thematic areas of biodiversity, climate change or desertification/land degradation, it may be possible to develop a harmonised strategy for all three conventions based on the structure of this work.

\section{Using the Self-Assessment as a Starting Point for Developing Action Plans and Project Funding Proposals}

One of the main objectives of the NCSA process is to facilitate the development of concrete project proposals for further consideration by GEF and other interested donors. For cross-cutting and synergetic projects, in particular, the boundaries between global and national environmental management are difficult to determine. Countries may therefore consider developing project proposals which strengthen the overall capacities both for national and global environmental management, with part of the funding originating from GEF and other parts originating from national and other external donors sources. In any case, a range of options exist for countries from choosing to not prepare a strategy/action plan to preparing a broadly-focussed plan. Some countries may wish to also develop a GEF-specific plan which builds upon the broadly-focussed plan.

\section{Monitoring and Evaluating the Implementation of a National Strategy/Action Plan}

An important aspect of implementing a strategy based on the NCSA involves continuously monitoring the progress in implementing activities (e.g. against the planned schedule or budget). ${ }^{29}$ Monitoring the implementation of activities can be based on three fundamental steps: measuring progress (in implementing activities); analysing the situation (to determine the cause of any positive or negative deviations from the plan); and determining necessary action (to remedy the situation whe re necessary).

Evaluating the impact of the strategy, i.e. ascertaining the degree of success in achieving the goal and objectives of the strategy, is also important. Evaluation can provide insight into what lessons can be learned to guide future efforts. Three simple questions can guide the evaluation process: to what degree were the agreed-to activities implemented? (see paragraph above); did these activities actually achieve the agreed-to goals and objectives?; and, if not, what further action is required?

\footnotetext{
${ }^{29}$ It may be desirable to also periodically review and update the NCSA document.
} 


\section{ANNEX A BACKGROUND ON THE INTERNATIONAL CONTEXT}

\section{Strategic Planning, Reporting and Capacity Building Under the Three Rio Conventions}

\section{The Convention on Biological Diversity}

Recognising the challenge for countries to accommodate the numerous decisions and programmes of the CBD related to capacity building, the COP initiated a process for countries to develop a strategic plan that would provide strategic and operational guidance for the implementation of the convention's policies and programmes. The main purpose of the strategy is to support and facilitate implementation of the convention by Parties, primarily through their National Biodiversity Strategies and Action Plans (NBSAPs). It will identify, as far as possible: planned activities; the expected products; the timing of each of these activities and products; the actors carrying out these activities and co-operation with relevant organisations; and the mechanisms used to realise and/or support the goals and activities, or to generate the expected products; and financial, human resource and other capacity requirements.

A number of projects have been implemented over the past years to assist countries in meeting the challenges of the CBD. For example, the GEF (UNDP and UNEP) Biodiversity Planning Support Programme was established to respond to needs recognised by the Parties to the CBD for strengthening national capacity to prepare and implement NBSAPs in compliance with Article 6 of the convention. The programme has three components that are implemented at the global and regional levels: (i) gathering and dissemination of specialised information on biodiversity planning and issues related to the CBD; (ii) developing guidelines, training modules and facilitating dissemination of "best practice" experience developed during the course of NBSAP preparation, and (iii) organising regional exchange and thematic workshops to promote intra-regional and global exchange of knowledge, experience and expertise.

\section{United Nations Framework Convention on Climate Change}

Recommendations under the UNFCCC call for strategic planning and action that are countrydriven and that, within the scope of capacity-building, each country should determine its specific objectives, needs, priorities and options to implement the convention. These should be consistent with the country's national sustainable development strategy and take into account existing capabilities and past and current activities.

Frameworks for capacity building in developing countries and countries with economies in transition, which set out the scope and basis for action on capacity building activities related to 
the convention, have been prepared by the Conference of the Parties (COP). ${ }^{30}$ They include, inter alia, the following elements:

- improve the co-ordination and effectiveness of capacity building efforts through dialogue between Parties and bilateral and multilateral institutions;

- continue to identify specific needs, options and priorities for capacity building on a country-driven basis; and

- promote the participation of a wide range of stakeholders, including governments at all levels, national and international organisations, civil society and the private sector, as appropriate.

Over the past years, a number of projects have been implemented in countries around the world to assist with national planning and reporting and strategic implementation of the convention. For example, the GEF-funded UNDP National Communications Support Programme has worked with more than 120 participating countries in 8 sub-regions and provides support through a helpdesk, technical support and workshops - to enhance the capacity of non-Annex I parties to prepare their initial National Communications. Prior to this UNDP Programme, the GEF/UNDP-funded UNITAR/UNFCC CC:Train Programme had assisted some 25 countries to produce their National Communications, to formulate a national strategy and to provide information about new technology through a series of workshops.

\section{United Nations Convention to Combat Desertification}

Article 19 of the convention ("Capacity building, education and public awareness") specifically recognises the significance of sound national planning and capacity building through, inter alia: institution building, training and development of relevant local and national capacities. Various consultations have identified capacity strengthening as one of the enabling activities for effective implementation of sub-regional programmes between neighbouring countries. Under the convention, participating countries are also obliged to prepare National Action Programmes (NAPs) to identify the factors contributing to desertification and to take practical measures necessary to combat desertification and mitigate the effects of drought. NAPs, which are developed in the framework of a participative approach involving the local communities, are strengthened by Action Programmes on the Sub-regional (SRAP) and Regional (RAP) levels. Moreover, the Thematic Programme Networks of the CCD in the various regions have been important avenues for addressing specific issue areas touching on institutional as well as

\footnotetext{
${ }^{30} \mathrm{UNFCCC}$, (FCCC/CP/2001/L.2), Review of the Implementation of Commitments and of Other Provisions of the Convention. Capacity-building. Draft decision proposed by the Co-Chairmen of the negotiating group, Draft decision -/CP.6, Capacity-building in developing countries (non-Annex I Parties) and UNFCCC, (FCCC/CP/2001/L.3), Review of the Implementation of Commitments and of Other Provisions of the Convention. Capacity-building. Draft decision proposed by the Co-Chairmen of the negotiating group, Draft decision -/CP.6, Capacity-building in countries with economies in transition. These draft decisions were forwarded to COP-7, where delegates will attempt to conclude their negotiations
} 
systemic capacity building. The process of developing NAPs has also been addressing capacity strengthening from the National Co-ordinating Body (NCB) standpoint, while the work of the Committee on Science and Technology (CST) has been addressing, inter alia, traditional knowledge, early warning systems, benchmarks and indicators.

In support of these provisions, a number of initiatives have been implemented. For example, the CCD Secretariat, in co-operation with UNITAR and l'Observatoire du Sahara et du Sahel (OSS), assisted concerned countries in Africa to prepare their National Reports according to article 26 of the convention and following the procedures adopted by the COP 1 . UNDP/UNSO developed and supported Capacity Building Workshops for Dryland Management and Implementation of the CCD. The workshops function principally as a capacity building enabling activity to support the development of country-driven processes and activities while providing a solid foundation of knowledge and understanding about the purpose and operations of UNDP/UNSO and the National Action Programme.

\section{Other Related Capacity Building Initiatives}

The GEF Country Dialogue Workshops (CDW) Programme, although not primarily a capacity building initiative, should also be noted here. This initiative implemented by UNDP/GEF seeks to promote country ownership of GEF co-financed activities, facilitate national co-ordination on countries' GEF programmes, and enhance awareness of the GEF. This is achieved by engaging in a direct two-way dialogue between the GEF and member countries through targeted, participatory workshops on the GEF and national priorities. During the first 16 months of implementation, 23 workshops have been conducted for 35 countries around the world.

The CDW programme brings together stakeholders from key government, NGO, academic/research and private institutions linked to the global conventions and instruments. The mostly national dialogues have successfully provided fora, similar to widely expanded "National Co-ordinating Platforms", to discuss strategic planning and reporting procedures related to the GEF and country obligations under each global convention and instrument, as well as a variety of cross cutting issues related to capacity development. The need for increased capacity building is often directly raised as a key priority during the broader CDW dialogues.

\section{Development of Integrated Approaches to Capacity Building to Protect the Global Environment}

The Capacity Development Initiative

In January 2000, the GEF Secretariat and UNDP launched the Capacity Development Initiative (CDI) - a consultative process involving outreach and dialogue to identify priority issues and capacity development needs in a number of regions and countries. These studies highlighted:

- a number of capacity development needs at the overall systems levels, commonalities in thematic issues and capacity development needs between regions (with some 
regional variations in emphasis), and the existence of synergies across conventions in terms of capacity needs; and

- the need to emphasise long-term programmatic approaches to capacity development that are driven by national teams encompassing a broad range of stakeholders and that reflect country priorities.

Another important conclusion of CDI was the need for national self-assessments of capacity building needs that are participatory, nationally-driven, and that receive needed technical and financial support; targeted capacity development initiatives that enable countries to address priority issues within the framework of global environmental conventions; and to revisit the way in which capacity building activities are being designed and implemented within the context of existing projects.

\section{Other Related Efforts}

Various efforts have been made to identify possible synergies under the Rio Conventions. These include, for example, a workshop organised and convened by UNDP of some 30 experts involved in implementing the Rio agreements at the national and international levels. ${ }^{31}$ The purpose of the meeting was to explore ways to create synergy between and among the instruments - particularly at the national level - to help foster implementation and improve the prospects for sustainable development. One outcome of the meeting was a range of preliminary proposals, options and recommendations to reduce conflicts and overlaps, and to produce synergy.

In addition, a series of national meetings to identify synergies among the three Rio Conventions has recently received support from the CCD Secretariat. For example, a recent workshop in Mongolia (The National Forum on Combating Desertification and Promoting the Synergistic Implementation of Interlinked Multilateral Environmental Conventions, 18-20 June 2001) examined the interwoven linkages between implementation of the CCD, CBD and UNFCCC as well as related multilateral environmental frameworks such as the Ramsar Convention on Wetlands and the Forest Principles. Specific opportunities to develop national information systems to address needs under the three Rio Conventions have also been discussed through workshops organised jointly by UNITAR and CILSS (Western Africa; June 1999) and IGAD (East Africa; March 2000) and which brought together the respective national focal points (CCD, CBD, UNFCCC).

Other efforts conducted under the three Rio Convention Secretariats include a review, initiated by the COP of the CCD, of activities for the promotion and strengthening of the CCD's

\footnotetext{
${ }^{31}$ UNDP, Synergies in National Implementation: The Rio Agreements; "Expert Meeting on Synergies Among the Conventions on Biological Diversity, Climate Change, Desertification and the Forest Principles", Sed Boqer, Israel, 17-20 March 1997.
} 
relationship with other relevant conventions (in particular, CBD, UNFCCC and the Ramsar Convention) and relevant international organisations, institutions and agencies. ${ }^{32}$

\section{Follow-up Action by the Global Environment Facility}

At its May 2001 meeting, the GEF Council approved a number of decisions regarding capacity building within and across the thematic areas of biodiversity, climate change and desertification/land degradation. The Council emphasised the need to undertake a more focused, strategic approach to capacity building for the global environment.

Specifically, the Council requested the GEF Secretariat:

- to initiate processes so that the self-assessment of capacity building needs can begin immediately in countries that request such assistance for them; and

- to consult with intergovernmental and non-governmental organisations participating in capacity building activities related to the global environment and sustainable development on the proposed strategic elements and framework for GEF action; ${ }^{33}$

In its deliberations, the Council emphasised the importance of promoting cross-convention synergies in capacity building activities in order to promote efficiency and quality. In this respect, the Secretariat was requested to clarify how the proposed framework for GEF action could lead to better co-ordination amongst the enabling activities for the conventions as well as the link between the proposals for capacity building and the evolving work on a programmatic approach. The GEF Council also emphasised that action for capacity building for the global environment should more explicitly take into account and be embedded in broader sustainable development strategies. ${ }^{34}$

\footnotetext{
${ }^{32}$ UNCCD, (ICCD/COP(3)/9), 28 September 1999, Collaboration and synergies among the Rio conventions for the implementation of the UNCCD.

${ }^{33}$ GEF, Joint Summary of the Chairs, GEF Council Meeting, May 9-11, 2001. "Decision on Agenda Item 7 [Gef/C.17/6/Rev.1], Elements of strategic collaboration and a framework for GEF action for capacity building for the global environment".

34 GEF, Joint Summary of the Chairs, GEF Council Meeting, May 911, 2001. "Highlights of the Council's Discussions: Agenda Item 7 [Gef/C.17/6/Rev.1], Results of the Capacity Development Initiative".
} 


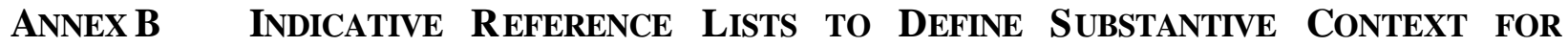 CAPACITY D EVELOPMENT UNDER EACH THEMATIC AREA}

\section{BIODIVERSITY ${ }^{35}$}

1. Effective National Biodiversity Planning

2. Identification and Monitoring of components of biological diversity important for its conservation and sustainable use

3. In-situ conservation of biological diversity

4. Respect for and preservation of knowledge, innovations and practices of indigenous and local communities

5. Ex-situ conservation of components of biological diversity, including for collection of biological resources from natural habitats for ex-situ conservation purposes

6. Develop and introduce economically and socially sound measures that act as incentives for the conservation and sustainable use of components of biological diversity.

7. Establish and maintain programmes for scientific and technical education and training

8. Promote and encourage understanding of the importance of, and the measures required for, the conservation of biological diversity

9. Introduce appropriate arrangements to ensure that environmental consequences of relevant programmes and policies are subject of environmental impact assessment and that significant adverse impacts on biological diversity are minimised

10. Develop and introduce appropriate measures to ensure safety regulations in handling living modified organisms resulting from biotechnology

11. Develop and introduce measures regulating the access to genetic resources and to provide access for and transfer to other Parties of technologies that are relevant to the conservation and sustainable use of biological diversity

12. Take legislative, administrative or policy measures, as appropriate, with the aim of sharing in a fair and equitable way the results of research and development and the benefits arising from the commercial and other utilisation of genetic resources

13. Establish and operate clearing-house mechanism to promote and facilitate technical and scientific co-operation

14. Implement Cartagena Protocol on Biosafety

15. Access financial resources provided via the financial mechanism of the Convention and/or via other donors

16. Other National Priorities (describe them)

\footnotetext{
${ }^{35}$ This reference list was used as part of a questionnaire administered by the CDI for the assessment phase of the CDI.
} 
CLIMATE CHANGE ${ }^{36}$

1. Institutional capacity-building, including the strengthening or establishment, as appropriate, of national climate change secretariats or national focal points

2. Enhancement and/or creation of an enabling environment

3. National communications

4. National climate change programmes

5. Greenhouse gas inventories, emission database management, and systems for collecting, managing and utlising activity data and emission factors

6. Vulnerability and adaptation assessment

7. Capacity-building for implementation of adaptation measures

8. Assessment for implementation of mitigation options

9. Research and systematic observation, including meteorological, hydrological and climatological services

10. Development and transfer of technology

11. Improved decision-making, including assistance for participation in international negotiations

12. Clean development mechanisms

13. Needs arising out of the implementation of Article 4.8 and 4.9 of the Convention

14. Education, training and public awareness

15. Information and networking, including the establishment of databases

\footnotetext{
${ }^{36}$ This reference list is provided as a result of consultation with the UNFCCC Convention Secretariat and is an excerpt from: UNFCCC, (FCCC/CP/2001/L.2), Review of the Implementation of Commitments and of Other Provisions of the Convention. Capacity-building. Draft decision proposed by the Co-Chairmen of the negotiating group, group, Draft decision -/CP.6, Capacity-building in developing countries (non-Annex I Parties), p 6.
} 
DESERTIFICATION/LAND DEGRADATION ${ }^{37}$

1. Education and public awareness

2. Transfer, acquisition, adaptation and development of environmentally sound, economically viable and socially acceptable technology

3. Training and technology regarding the use of alternative, renewable energy sources (aimed particularly at reducing dependence on wood for fuel)

4. Promotion of alternative livelihoods, including training in new skills

5. Training of decision-makers, managers and personnel responsible for collection and analysis of data for disseminating and using early warning information on drought conditions, water resources and for food production

6. Information collection, analysis and exchange (relevant short-term and long-term data and information; particularly to ensure systematic observation of land degradation in affected areas and to better understand and assess the processes and effects of drought and desertification)

7. Effective early warning and advance planning for periods of adverse climatic variation (provided in appropriate forms)

8. Research and development

9. Technical and scientific co-operation in the fields of combating desertification and mitigating the effects of drought through appropriate national, sub-regional and international institutions

10. Joint research programmes (also involving public and private sector) for the development of improved, affordable and accessible technologies for sustainable development

\footnotetext{
${ }^{37}$ This reference list is provided as a result of consultation with the CCD Convention Secretariat.
} 


\section{Annex C Overlapping Requirements of the Parties to the Rio Conventions EXEMPLIFIED BY SELECTED ARTICLES}

\begin{tabular}{|c|c|c|c|}
\hline & Biodiversity & Climate Change & $\begin{array}{c}\text { Desertification/Land } \\
\text { Degradation }\end{array}$ \\
\hline National inventories & & Article 4 (b) & \\
\hline $\begin{array}{l}\text { National and regional } \\
\text { action plans }\end{array}$ & $\begin{array}{l}\text { "strategies" Article } 6 \\
\text { (a), (b) }\end{array}$ & Article 4 (b) & Articles 9,10 \\
\hline $\begin{array}{l}\text { Identification and } \\
\text { monitoring }\end{array}$ & Article 8 & & Article 16 \\
\hline $\begin{array}{l}\text { Develop protected } \\
\text { areas }\end{array}$ & Article 8 & & \\
\hline Legislation & Article $8(\mathrm{k})$ & Preamble & Article 5 (e) \\
\hline Research & Article $12(\mathrm{~b})$ & Article 5 & Articles 17, 19 (b) \\
\hline Public education & Article 13 & Article 6 & Articles 5 (d), 19, 6 \\
\hline $\begin{array}{l}\text { Environmental impact } \\
\text { assessment }\end{array}$ & Article 14 & Article 4 (i) (d) & \\
\hline $\begin{array}{l}\text { Clearing house for } \\
\text { technical information }\end{array}$ & Article 18 & & Article 18 \\
\hline Public participation & Article 9 & Article 6 (i) (a) (iii) & Article $19(4)$ \\
\hline Information exchange & Article 17 & Article 7 & Article 16 \\
\hline Training & Article $12(a)$ & Articles 6 & Article 19 \\
\hline Reports & Article 26 & Article 12 & \\
\hline Data collection & & & Article 16 \\
\hline $\begin{array}{l}\text { Examine obligations - } \\
\text { assess implementation }\end{array}$ & Article 23 & Article 7 (e) & \\
\hline Report steps to COP & Article 26 & Articles 12 & Article 26 \\
\hline
\end{tabular}

Source: UNDP, Synergies in National Implementation: The Rio Agreements. 
$\longrightarrow$

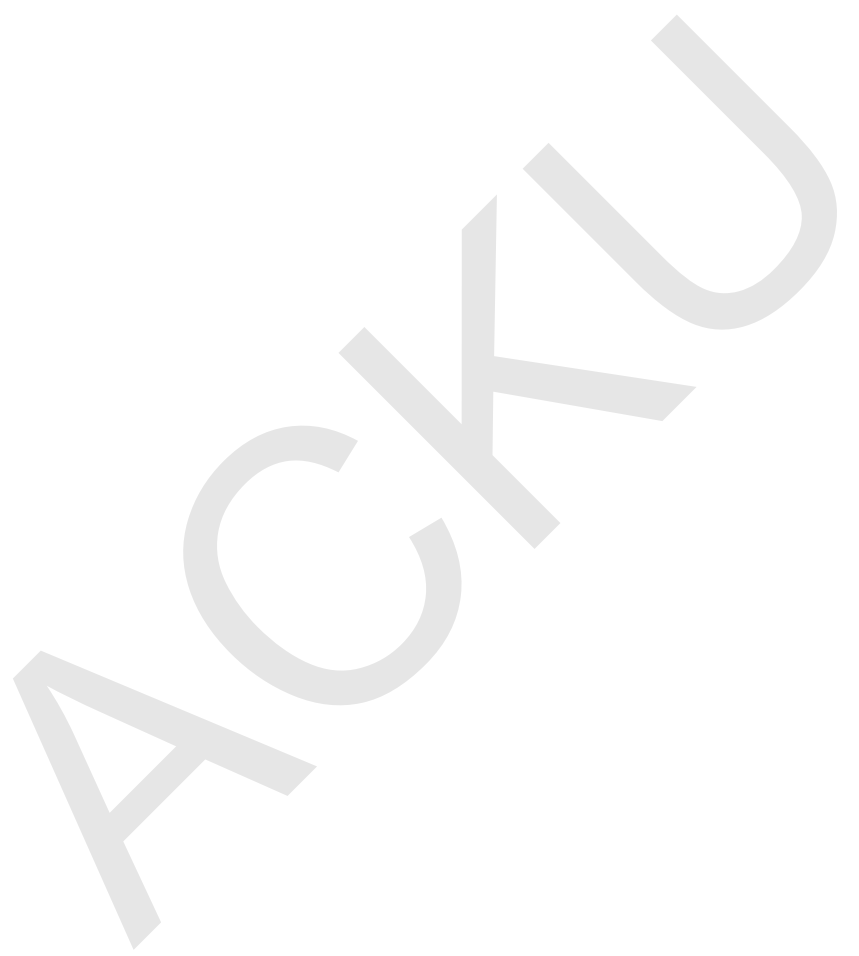

